\title{
Implementation of E-Health Record Systems and E-Medical Record Systems in China
}

\author{
Xiangzhu Gao, Jun Xu, Golam Sorwar \& Peter Croll \\ Southern Cross Business School, Southern Cross University \\ Lismore, NSW 2480, Australia \\ E-mail: xiangzhu.gao@scu.edu.au
}

\begin{abstract}
In 2005, Chinese government defined its direction to electronic health records and electronic medical records. Up to 2012, hundreds of electronic health record systems and electronic medical systems have been developed, but the systems are still in their infancy, and China is facing a variety of challenges in implementation of the systems. To overcome the challenges and achieve system benefits, recommendations are provided for implementing a national electronic health system.
\end{abstract}

Keywords: E-health, E-health Record System, E-medical Record System, China

\section{Introduction}

From 2000 to 2010, Chinese population increased by $5.84 \%$, reaching 1.34 billion according to the 6th national census ${ }^{1}$. To meet the needs of the healthcare for such a large population and to improve healthcare services, China increased its annual health expenditure dramatically by $335 \%$ from CN¥460 billion in 2000 to CN¥2000 billion in 2010, according to the Ministry of Health (MOH) of China ${ }^{2}$. Over these years the healthcare infrastructure in China has been well developed. In 2011 there were 954,389 health institutions, including 21,979 hospitals, 918,000 grassroots or community health service centres (CHSCs), and 11,926 specialised public health institutions. However, as China is a developing country with a large population, China's health expenditure per capita is much lower than that of developed countries. In 2008, China's health expenditure per capita was US\$146, contrasting US’s US\$7,164, France’s US\$4,966, Germany’s US\$4,720, Canada’s US\$4,445, Australia’s US $\$ 4,180$, UK’s US\$3,771 and Japan's US\$3,190². To further improve its healthcare, China must improve the efficiency of its healthcare services while maintaining lower costs, in addition to the increase in government budget.

The Chinese government laid a focus on healthcare sector in its 12th Five-Year Plan (2011-2016). MOH defined its 3521 project for e-health, where the ' 3 ' refers to three levels of healthcare data platform: country, province and region levels; the ' 5 ' points to five applications: public health, medical services, new rural medial insurance plan, basic drug plan, and general management; the ' 2 ' indicates two systems: electronic health record (EHR) system and electronic medical record (EMR) system; and the ' 1 ' represents one special network for healthcare ${ }^{3,4,5}$. Regarding the EHR and EMR, a health record is the information of health conditions about a healthcare recipient ${ }^{6}$ at CHSCs or other health institutions, while a medical record is the information of hospital clinic and therapy about a medical care recipient ${ }^{7}$. EHRs are collected, stored and shared by regional CHSCs, while EMRs are recorded or generated, stored and shared by hospitals.

The Chinese government leads the development of EHR and EMR systems. The MOH approved the establishment of professional committees for research on and development of standards and specifications. The China Hospital Information Management Association (CHIMA) focuses on the preparation of management specification and regulations for digital hospitalisation standards ${ }^{8}$. The Health Information Standards Professional Committee (HISPC) of the $\mathrm{MOH}$ prepared a series of guidebooks, standards and specifications for both EHR and EMR systems. In 
addition, the government has developed supportive ehealth policies including national e-health policy, national multiculturalism policy for e-health, national telemedicine policy, and e-government policy.

China's e-health system development is significantly affected by its economy, administration, geography, demography and culture. Economic development in China is extremely unbalanced. Urban development is faster than rural development, and growth in eastern regions is faster than that in western regions. There is growing inequity in health status, resource allocation and service delivery between rural and urban areas ${ }^{9}$. The Chinese population is rapidly aging, due to a lower mortality rate and the one-child policy, which was forced to implement in 1979. In 2010, rural residents were over 674 million (50.32\%); mobile population was over 261 million (19.07\%); and elderly residents over 60 years old were over 177 million (13.26\%) ${ }^{1}$. These features have led to healthcare challenges for the central government, which announced a comprehensive healthcare reform in 2009 to address the issues without a detailed roadmap ${ }^{10}$.

The healthcare reform boosted CHSCs in urban areas to play an important role in prevention, medical care, rehabilitation and health promotion. The CHSCs are non-profit institutions, and their service targets are women, children, elderly people, chronically sick and disabled people and poor residents in residence communities. The communities are partitioned based on the administrative areas where households are registered according to China's household registration system. A household registration record includes the members of a family as residents of an administrative area and identifies each member's information of name, gender, date of birth and the relationship with the householder (parent, spouse, etc.). The household registration records, and the roles and targets of the CHSCs affect the implementation of EHR systems.

\section{Current Status}

According to $\mathrm{CHIMA}^{8}$ computerisation in hospitals in China started in late 1980s. Some economically advanced cities started to develop regional EHR systems in $2002^{11}$. In this paper, however, the authors only review relevant efforts and results since 2005 for the reason that major activities and significant events have happened since then. The development of EHR and EMR systems in China is marked with the following milestones.

- In 2005, the 5th Plenum of the 16th Communist Party Central Committee passed its suggestion for the 11th Five-Year Plan ${ }^{12}$, which directed the development of EHR systems and EMR systems.

- In 2006, the HISPC was established by the $\mathrm{MOH}$ for standards creation, administrative certification and application promotion ${ }^{13}$.

- In 2009, the MOH issued the Guidebook for Creating Regional Health Information Platform Based on Electronic Health Records, which describes operation flow, and information and functionality of the platform, providing IT vendors with clear system requirements ${ }^{14}$.

- In 2009, a series of standards and specifications were published by $\mathrm{MOH}$, including Basic Structure and Data Standards for Health Records ${ }^{15}$, Basic Dataset Compilation Specification for Health Records $^{16}$, Common Data Elements in Health Records $^{17}$, and Basic Dataset of Personal Information $^{18}$.

- In 2009, Beijing, Shanghai, Guangzhou, Xiamen, and Hangzhou, which are economically advanced cities in China, saw their initial achievements in EHR system initiatives ${ }^{11}$.

- In 2010, MOH developed Basic Standard for Electronic Medical Records.

- In 2010, Shanghai, Zhejiang, Anhui, Chongqing, and Xinjiang, which are located from east through west in China, participated in testing EHR and EMR systems sponsored by $\mathrm{MOH}^{5}$.

- In 2011, the Guidebook for Creating Integrated Administration Platform for Health Records was released by MOE, which includes functional requirements and design concepts for the Platform, and provides health administrators and decision makers with information support and service ${ }^{19}$.

- In 2011, the MOH published the Technical Solution for Developing Hospital Information Platform Based on Electronic Medical Records ${ }^{20}$.

- In 2012, the MOH published the Specification for Sharing Documents of Health Information ${ }^{6}$, and the Specification for Sharing Documents of Electronic Medical Records ${ }^{7}$. 
- In 2012, the State Council ${ }^{21}$ published the 12th Five-Year Plan for Developing Health Services, which includes establishment of a national unified medical and health information standard system.

In planning for the EHR and EMR systems, China studied international experiences from US, UK, Canada, Australia, etc. For example, China's EMR systems adopt the HL7 Standard ${ }^{20}$, which takes an important position in the US standard system and has become an international standard for medical information exchange $^{22}$. Because of the complexity of EHR systems, Australia has taken 3 stages to reach a national system: MediConnect, which was a pilot system ${ }^{23}$; HealthConnect, which consisted of seven regional systems $^{24}$; and Personal Controlled Electronic Health Record (PCEHR) System, which is a national system ${ }^{25}$. China follows a similar procedure in deploying EHR systems. Both local and international vendors have provided solutions for China's EMR/EHR systems. Popular international vendors include IBM, Dell, Cisco, Siemens and Fujitsu, and main Chinese vendors are Yonyou, DHC, Neusoft, B-Soft, Winning, Founder and Jiangsu Zhongkang Software. Different hospitals use different EMR systems ${ }^{26,27}$.

By 2009, China had completed its pilot test of the EHR systems in major cities ${ }^{11}$. In 2010, fund is allocated for EHR initiatives in five provinces ${ }^{5}$. In these stages of EHR attempts at regional and provincial levels, some cities or provinces developed their own standards and systems. Based on these systems, the $\mathrm{MOH}$ developed standards and specifications for subsequent stages. Until 2011, 120 EHR systems had been completed, 40 systems were under development and 100 systems were in planning phase ${ }^{19}$. The 2009 Guidebook $^{14}$ required that by $201150 \%$ urban residents and $30 \%$ rural residents will have their e-health records and by 2020 all residents will have their own e-health records. The Minister of $\mathrm{MOH}$ declared on Feb 27, 2012 that 900 million residents had created their health records, accounting for $66 \%$ of the national population, and more than $50 \%$ of residents had created their ehealth records ${ }^{28}$. It is planned that $75 \%$ of urban residents will have their EHRs by $2015^{21}$.

The Basic Structure and Data Standards for Health Records ${ }^{15}$ defines that health records consist of personal information and the records of health services at health service institutions, including children's health, women's health, disease management, disease control and medical service. These are typical services provided by CHSCs, which are in charge of resident registration with and data entry to EHR systems. To meet MOH's targets of EHR adoption, local governments encourage CHSCs to register residents by incentive per registration. CHSCs visit residents at home or use residents' household information from local police stations. As the data are collected as a result of administrative intervention instead of the results recorded when individuals receive health services, the information could be incomplete and inaccurate. The authors interviewed some residents in Beijing, Tianjin, Baoding, Dalian, Shenyang, Changchun and Wuhan during October 2012 to January 2013, and found out that none of them has personally accessed to EHR systems, and most of them do not know EHR systems. Currently EHR systems are used by CHSCs to store health information of local residents in stand-alone computers.

Governments at different levels have been working on information exchange between communities by establishing Regional Healthcare Information Networks (RHINs), which utilise data centres and telecommunication networks to share data and clinical services among geographically dispersed communities $^{29}$. More efforts will be put into RHINs in the coming years. For example, Jiangsu Zhongkang Software Co., Ltd. and Nantong University have developed a Web platform (www.chinaehr.org) according to the Basic Structure and Data Standards for Health Records ${ }^{15}$. The platform is designed to be used by individuals and healthcare providers in Jiangsu Province and, possibly, other 12 provinces. Currently the platform invites medical doctors from CHSCs in Nantong, Jiangsu to participate.

Regarding EMR systems, there exist many standalone and scatted efforts across the country. IT vendors have worked with hospitals to provide solutions for EMR systems. Reported examples include:

- IBM has developed a series of solutions, including Clinical and Medical Record Analysis and Sharing System (CHAS) for a hospital in Guangdong ${ }^{30}$, and Cloud Solution for sharing clinical data ${ }^{31}$.

- Cisco $^{32}$ developed an Integrated Solution for Digital Hospitals for Peking University People’s Hospital. 
- Dell provided its solution of virtual technology to

help Xiamen University Zhongshan Hospital upgrade its existing systems ${ }^{33}$.

Early in 2008, 80\% of hospitals had implemented a hospital information system of a kind. According to $\mathrm{MOH}^{2}$ there are 21,979 hospitals in China. This means that about 17,583 hospitals have installed or used information systems for medical purposes or supporting activities.

Hospitals have developed EMR systems without a consideration to share information with EHR systems. However, efforts have been made in sharing information with EMR systems when developing EHR systems by local governments. Xiamen has successfully attempted the association of an EHR system with an EMR system. In Xiamen's system, which involves 95 medical institutions and $60 \%$ of local residents, health information, medical treatment records and check-up results of a resident since birth are recorded in one data repository ${ }^{34}$. Health Cards is another major project relating to connecting EHR and EMR. The system will link hospitals, public health institutions, and insurance operations across China. Currently, the system has been piloted in Henan, Liaoning, Guangdong and Inner Mongolia ${ }^{4}$.

\section{Challenges and Issues}

\subsection{Insufficient Fund and Biased Fund Allocation}

E-health projects are expensive ${ }^{35}$. For example, U.S. invested AU\$28 billion (AU\$1,320 per capita) in the Barack Obama Plan in five years, and Australia has already spent AU\$466.7 million (AU\$21 per capita) on the first release of the PCEHR system in two years ${ }^{36}$. According to World Health Organization (WHO), lack of funding is one of the major hurdles affecting ehealthcare adoption in developing countries including China $^{37}$. It is estimated that the required investment in hardware/software is CN¥26 billion (CN¥20 per capita) ${ }^{11,38}$. Normally hardware/software accounts for $20 \%$ of the development cost ${ }^{39}$. Therefore development cost would be CN¥130 billion (CN¥100 per capita or AU\$17 per capita). Generally speaking, the annual cost to maintain an e-commerce or e-government system in its operation phase is between $50 \%$ and $200 \%$ of the cost for the development phase ${ }^{39}$. According to this rule,
China needs CN¥65 to CN¥260 billion annually to maintain the systems. Although the total healthcare expenditure was CN¥2000 billion in 2010, the government contribution is CN¥573 billion only ${ }^{1}$. Obviously, government healthcare budget cannot provide sufficient fund for system operation.

China has invested its limited fund for e-health unevenly ${ }^{26,40}$. According to Ying ${ }^{41}, 64.7 \%$ of the fund was allocated to computer hardware. Contrasted with the normal $20 \%$ cost by hardware/software, the large proportion of fund for hardware indicates a lack of research on and analysis of EHR and EMR systems. Moreover, while over $50 \%$ of the total population live in rural areas ${ }^{1}$, where healthcare infrastructure typically lags behind, the government allocates $41 \%$ of its fund for 2009-2011 to rural health ${ }^{29}$. The biased fund allocation poses more difficulties in implementing EHR or EMR systems in rural areas.

\subsection{Lack of Unified Planning and Governance}

Hundreds of EHR and EMR systems are developed or are operating in different regions with no or little crossregion data sharing. There is not central governance over regional development and unified planning for a national system. In 2004, the Chinese Health Information Society established the Health Information Standardisation Professional Committee (CHISHISPC). In spite of the existence of CHIS-HISPC, $\mathrm{MOH}$ established its HISPC in 2006. The two committees are partly overlapped their roles and/or functionality. Although the $\mathrm{MOH}$ has issued standards for EHR and EMR systems, these standards are not clear and difficult to follow in practice ${ }^{42}$. Some regional governments have developed local standards, hoping their efforts to become accepted as 'golden pilots" ${ }^{29}$. For example Zhejiang Bureau of Quality and Technical Supervision ${ }^{43}$ developed the Technical Specification of Access Interface for Sharing Health Data.

Because of the lack of unified national approach, clear planning and governance framework, the quality of the EHR and EMR systems and the productivity of the development are low. A large amount of resources have been used for repetitive products that are isolated from each other. The authors visited some hospitals in Beijing and CHSCs in Tianjin in 2012 and found that new patients have to fill in registration forms, which 
capture different information at different hospitals, and resident health records are stored in CHSCs' standalone computers.

There is not general guidance and it is individual doctors' decision to share medical or health information between medical or health institutions. Hospitals have not formed positive attitude towards sharing information for reasons such as self-funded systems, propriety, concern of disclosing critical information to outsiders, and the fear of criticism by fellow professionals. Large and metropolitan hospitals are typically not willing to share information with their smaller counterparts or CHSCs even though the latter is keen on sharing information with the former. Doctors from large hospital tend not to recognise diagnosis and test results from smaller hospitals because of the concern about personnel's proficiency and instrument's accuracy.

\subsection{Lack of Willingness to Share Information}

There is not general guidance and it is individual doctors' decision to share medical or health information between medical or health institutions. Hospitals have not formed positive attitude towards sharing information for reasons such as self-funded systems, propriety, concern of disclosing critical information to outsiders, and the fear of criticism by fellow professionals. Large and metropolitan hospitals are typically not willing to share information with their smaller counterparts or CHSCs even though the latter is keen on sharing information with the former. Doctors from large hospital tend not to recognise diagnosis and test results from smaller hospitals because of the concern about personnel's proficiency and instrument's accuracy.

\subsection{Issue of Two Separate Systems}

EHR systems and EMR systems are regarded as different systems and operate in parallel respectively. EHRs are entered by CHSCs and EMRs are recorded in hospitals. Quality of data in EHR systems is uncertain because of unrealistic target that 50\% urban residents and 30\% rural residents would have their EHRs by 2011. The authors visited a CHSC, which takes charge of 93,336 residents and stores their EHRs in a database hosted in a stand-alone computer. If it takes 5 minutes to enter one person's EHR, and data entry continues 8 hours per day, it needs 486 working days to reach the target. Data collected in haste may not be complete and/or accurate. However much information included in EHR systems can be obtained from EMR systems ${ }^{20}$, where information is obtained when patients visit hospitals and therefore should be more accurate.

In 2012, $\mathrm{MOH}^{6,7}$ published standards or specifications for each of the two systems with an objective of interaction between the two systems. However, beside the issue of interoperability, developing both EHR and EMR systems consumes the insufficient resources while reinventing the wheel. Later in the same year, the State Council ${ }^{21}$ planned to establish a national unified medical and health information standard system. However, there will be integrity issue regarding data from the two legacy systems, which must be addressed now.

\subsection{Lack of Legislation and Regulation}

Private data should be secret from non-expected users (secrecy), data should be available for meaningful use (necessity) and critical data must be correct and accurate (integrity), when data are stored in and transmitted between systems ${ }^{37}$. Even though security techniques such as authentication and encryption can address these issues, legislation is necessary to define private data, and regulate meaningful use and trustful operation of the systems.

Secrecy and necessity may conflict and must be balanced in system analysis and design. Low level of secrecy increases the risk of privacy breach while increasing necessity, and low level of necessity may cause negative impacts on health ${ }^{44}$ while improving secrecy. Currently there is a lack of policy and regulation in China for recording, storing and using personal health information ${ }^{11,37}$, and EHR and EMR systems are developed and implemented without relevant guidance. For example, EHR system users are identified by national ID number, which includes personal identifiable information of residence area and date of birth, and individuals can access their EHRs with ID cards ${ }^{45}$.

\subsection{Issue of Interoperability}

EHR and EMR systems are complex and integrate multiple techniques ${ }^{46,47}$. China's EHR and EMR systems are developed by various vendors of software 
firms, universities, research institutions, etc. Most of these systems are isolated. The aim of these systems is to meet specific needs of the healthcare institutions, including demographics, diagnosis and payment ${ }^{48}$ without consideration for interoperability. China has issued its standards, but interoperation of EHR or EMR systems is more complex than standards could define, and software engineering solutions should be sought ${ }^{49}$. Moreover, the current standards should be improved. For example, the Basic Structure and Data Standards for Health Records ${ }^{15}$ has some critical deficiencies in terms of privacy and security, support for different data types and reference data, mechanism to support easy additions and extensions to various medical domains and organisations, and relational attributes for data elements $^{50}$.

\subsection{Issue of E-health Talent and Research}

Health and medical informatics education and training in China cannot meet China's need ${ }^{51}$. There is a lack of skilled health IT professionals to develop health IT solutions $^{52}$ and the talent to combine IT knowledge/skills, healthcare, nursing and public health ${ }^{42,53}$. The authors noticed that it is difficult to obtain literature of theory on e-health in China. This indicates a lack of theory support for developing ehealth information systems in China, which is primarily gained from research ${ }^{38,54}$. Meanwhile, there is a need for EHR system education. According to Huang ${ }^{11}$, data for EHR systems are mainly collected in urban communities and rural villages from women, children, elderlies, chronically sick and disabled people, who are the main targeted users of China's EHR systems. Compared with others, this group of people is averagely at lower levels in IT literacy. There is a need for EHR system education among these people.

\section{Recommendations and Outlook}

\subsection{Developing a National System of Hierarchical Structure}

Although there are hundreds of EHR and EMR systems, these systems will have to be abandoned or upgraded eventually because of the challenges to and defects with them. According to international experiences and the 12th Five-Year Plan by State Council ${ }^{21}$, China will eventually build its national unified electronic health/medical record (EH/MR) system. Because of unbalanced economy across the country, insufficient fund and biased fund allocation, difference in regional policies and difference in resources and organisations in different areas, the national EH/MR system should evolve in a top-down approach towards a hierarchical structure with 3 levels of country, province and region, as defined in the 3521 e-health project by $\mathrm{MOH}$. The system will be developed in object oriented (OO) approach $^{55,56}$ to allow

- Inheritance - a child class at a lower level (province or region) inherits features and methods from its parent class at a higher level (country or province) to ensure that a province or region carries out standards, policies, etc. from the country or the governing province, and avoids repetition at lower levels;

- Overriding - a child class can implement the methods inherited from the parent class differently to ensure that a province or a region can be different from another one at the same level;

- Encapsulation - a class is independent from others to ensure that the change (participation, withdrawal, local reform, etc.) in the class will not affect other classes; and

- Polymorphism - objects in a class (institutions in a province or region) can have specific implementation of user interfaces to ensure that the system is usable for different users including hospitals, CHSCs and individuals.

Figure 1.1 illustrates the class diagram of the national unified system. The Country is the top level class. Province1 through ProvinceN are related to $\mathrm{N}$ provinces (including municipalities) in terms of implementing $\mathrm{EH} / \mathrm{MRs}$. If two or more provinces implement EH/MRs in exactly the same way, they are technically regarded as one province. The Region1.1 through RegionN.M are related to regions in respective provinces. Because of the encapsulation, classes can be easily added under a region class to adapt the EH/MR system to possible variety within regions. 


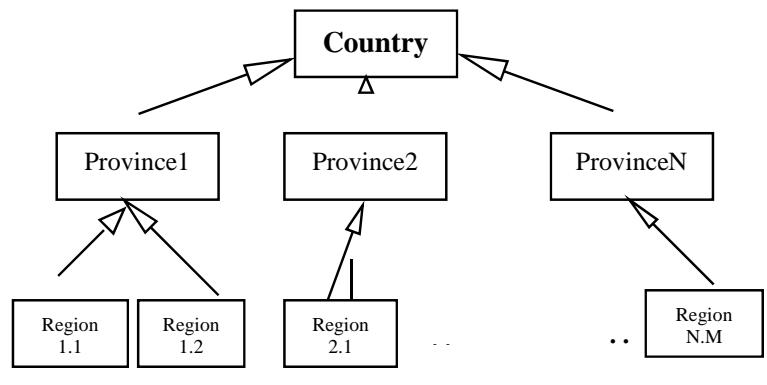

Fig. 1. Hierarchical structure of the national EH/MR system

The features of this approach are

- The hierarchical structure conforms to China's administrative structure.

- The system is developed incrementally according to the national e-health plan, and in order to meet the challenge of insufficient funds. The system can be used at a higher level while it is developed for a lower level.

- The system is maintainable to accommodate China's changing environments.

- $\quad$ The system is sustainable and will become simpler with the change towards balanced economy and unbiased fund allocation.

$\mathrm{MOH}$ will lead and govern the complete process of system development and implementation, although local governments will be involved in timely stages.

\subsection{Using Smart Cards at the Present Time}

Citizens will participate in the national system at different stages of the system development, which may take years of time. According to State Council ${ }^{21}$, the number of individual EHR users will increase from 50\% to $75 \%$ of the residents from 2012 to 2015. Based on this rate, it is estimated that all residents will use EHRs in 2018, when the national system evolves to be complete. In the next 5 years, people need to use current systems and will be gradually transferred to the national system. China produces a huge amount of clinical documentation every year ${ }^{50}$. According to a research based on a hospital in China, the hospital creates more than 20,000 new inpatient records per year ${ }^{57}$. Such records need to be shared between existing EHR/EMR systems, and past data need to be transferred into the future system. Smart cards would be a cost-effective method for sharing and transferring the records.

An individual holds his or her EHR card, with which the individual can access to existing EHR or EMR systems to download, append, edit or upload EHR/EMRs. The card holder controls the operation on his/her information.

The features of using smart cards are:
- $\quad$ Chinese people are used to keeping medical records with themselves. They had a history to keep medical records by individuals before computers are used to store the records.

- $\quad$ They are used to using smart cards. Most people are using medical insurance cards and other types of cards.

- Smart cards are cost-effective and easy to use ${ }^{58}$. The smart cards do not need computer networks, except for cards and card readers.

- Smart cards can store more complete and better quality data, which may be integrated from multiple institutions $^{59}$. When inconsistency is noticed, human intervention will fix errors.

- Card holders control the access to their EHRs/EMRs.

- Smart cards are in practice impossible to forge or unlawfully manipulate. Strong offline and/or online verification (PIN or biometric) limits the unlawful use of lost or stolen cards to gain access to healthcare ${ }^{58}$.

- The smart cards will be the media from which $\mathrm{EH} / \mathrm{MRs}$ are transferred to the national system in the future.

\subsection{Establishing Incentive Mechanism}

Appropriate incentive mechanism is essential for implementing EHR and EMR systems. For adopting the PCEHR system, Australian government requires clinics to participate, otherwise the clinics would become ineligible for the eHealth $\mathrm{PIP}^{60}$, which is part of a blended payment approach. Similar as the PIP, China's Social Insurance Scheme (SIS) allows patients to pay their own portion of fees at a hospital, and the hospital will be compensated for the remaining fees from the SIS. China can learn from Australia to enforce that SIS system only links to the national EH/MR system.

Chinese government allows hospitals to develop higher quality services, for which they can charge prices above the levels reimbursed by SIS. The charge for higher quality services is one of the revenues that produce hospital gains ${ }^{61}$. Governments should require that higher quality services, including non-ensured drug sale and testing referral, are processed only by the national EH/MR system.

Australian government provides fund to support clinics to develop their e-health capability ${ }^{60}$. It is more necessary for Chinese governments to provide funds to 
help CHSCs, county hospitals and township clinics develop their EHR capability.

\subsection{Ensuring Sustainable Fund}

According to software engineering research ${ }^{62}$ and international EHR experience ${ }^{35,63}$, system maintenance for successful operation will cost much more than its development. Sustainable fund is needed for adopting EHRs and EMRs.

China's national health and medical budget has been among the lowest in the world ${ }^{37}$. Patients have to pay $37 \%$ of the fee ${ }^{64}$ for healthcare services. It is a heavy burden for many of them, and some of them cannot afford for professional services ${ }^{65}$. Patients should not take financial responsibilities in implementing the national system. It is the same for public hospitals, as any additional cost on them will be transferred to patients. The governments should increase their budgets for the national EH/MR system, and raise funds from other sources:

- E-health levy from high income taxpayers - In the context of healthcare services, citizens assume two major roles: collective taxpayers and individual users of services ${ }^{66,67,68}$. Australia has been temporarily collecting flood levy since 2011, which applies to every taxpayer who has a taxable income of more than AU\$50,000 a year, to raise fund for rebuilding flood-affected regions in Queensland. In 2011-2012, the levy raised AU\$1.8 billion, and cost average income earners $\$ 1.74$ a week $^{69}$. China can also raise funds for e-health in a similar way.

- E-health contribution from international private hospitals - Chinese middle class is willing to pay more for quality healthcare, and foreign investors are keen to meet this demand ${ }^{70}$. The number of private hospitals and clinics in China grows at $20.6 \%$ annually, according to IMAPAC ${ }^{71}$. Foreign players charge at least 40 times more than public hospitals ${ }^{70}$. They will benefit from and should contribute to the national system.

- Re-allocation of government budget from year to year - With the development progress of the national system, some medical institutions participate in the system and enjoy the benefits earlier than others. For example, it is estimated that redundancy and inefficiency account for $25-40 \%$ of costs in Europe ${ }^{72}$. EHR is capable of increasing efficiency in processing data and transferring information. The governments should re-allocate budget each year with more support for EHR initiatives.

World Bank $^{73}$ pointed out that China could potentially aim to increase public expenditures by 2-3 percentage points of GDP, which was CN¥51,932,210 million in $2012^{74}$, for healthcare. The increase could be more than CN¥1.04-1.56 trillion. There is great potential for government to increase budget for the national EHR system.

\subsection{Working on Privacy Issues}

Many data in EHRs and EMRs are highly sensitive in terms of privacy, necessity and integrity, and need to be dealt with extra caution. However these issues have not caused significant attention ${ }^{75,76}$, especially privacy issue, which is a major obstacle to implementing EHR in Australia and many other western countries. There may be two main reasons for the omission of the privacy issue. Firstly, there is a lack of emphasis on personal privacy in Chinese traditional culture. Secondly, there has not been large-scale health data exchange and, therefore, no serious privacy violation has been notified. A study ${ }^{77}$ suggested that adoption of e-health would only be successful if healthcare providers and governments can assure the privacy. China should address the privacy issue in system development.

E-health specific laws are necessary to guarantee privacy protection ${ }^{78}$, but very few countries have established comprehensive legal framework on EHRs ${ }^{79}$. In Australia, EHR is protected based on Commonwealth Privacy Act 1988 and regional privacy laws depending on where the EHR system is operated and used ${ }^{25}$. China does not have but should eventually establish privacy laws. However, China should not wait until the emergence of the laws to implement its EHR system, but create a code of conduct with reference to privacy protection in EHR systems with efforts from governments, medical professionals, legal professionals, information technology experts and individual users. In creation of the code, China should learn successful practices from international experience and consider the Chinese tolerant culture in using some personal information. Medical professionals and the public will be educated with the code, and system analysts and designers will determine and design for privacy requirements based on the code. 


\subsection{Developing EHR Knowledge and Skills}

Adoption of national EHR system faces different challenges - clinical, political, technical, cultural/emotional, organisational, legal, and financial $^{72,80}$. Systematic research on EHR/EMR initiative and EHR education is needed in China. Currently hospitals require staff to use EMR system, and the staff learn to use the system by teaching themselves. They use an EMR system only as a digital form of traditional paper records regardless of system's added values. Individuals do not have access to the systems. The EHR research and education are needed:

- Government sponsor and guide EHR research on strategies, policies, regulations, standards, framework, and system development and implementation. Researchers from multiple professions should be involved, including medicine and health, information technology, law, management and society.

- Healthcare or medical institutions should provide trainings for knowledge about national system and skills to make best use of it. Government can teach individuals to use the system using existing resources such as TV health programs, TV courses and online tutorials.

According to $\mathrm{WHO}^{37}$, China has been working on developing e-health capacity building in recent years through ICT training and education for health students and health professionals. It is expected that the problem of lack of talent and skill will be solved in a few years.

\subsection{Working on Mobile Health}

Currently China has not taken an initiative to access EHRs using mobile devices. However, the large mobile population and mobile phone population determine the significance of mobile health (m-health) in China. As a result of unbalanced economy, many people from impoverished regions go to urban and prosperous coastal regions in search for work. These people construct the majority of the mobile population. They rely on mobile devices more than cabled computers to access the Internet. Moreover, China has 400 million mobile Web users and is world's top smartphone market ${ }^{81}$. China should develop a mobile version for the national system, which will realise the benefits of remote monitoring using mobile devices based on the concept of Internet of Things ${ }^{82,83}$.

\subsection{Moving towards Cross-country Data Exchange}

International travelers to China reached 27.11 million person-trips in $2011^{84}$, and Chinese travelers to other countries reached 83.18 million person-trips in $2012^{85}$. Some people travel for international medical services. There is a need for cross-country EHR exchange mechanism and platform. Although sharing EHRs with other countries is not in China's national agenda, local attempts have been taken in this regard. For example, Zhejing University has been working on a collaborative effort with Kyoto University and Miyazaki University in Japan to obtain clinical information between China and $\operatorname{Japan}^{57}$. Moreover, in developing a national system, China needs to address the issue of difference between provinces or regions. China will acquire experience from cross-border for cross-country sharing of EHR information.

\section{Acknowledgement}

This research is supported by Australian Government under the Australia-China Science and Research Fund.

\section{References}

1. National Bureau of Statistics of China, 2010 Data Bulletin of the $6^{\text {th }}$ National Census (Apr 28, 2011 in Chinese), Online available at

http://www.stats.gov.cn/tjfx/jdfx/t20110428_402722253.h tm (accessed Oct 2, 2012).

2. MOH, 2012 China Health Statistics (Executive Summary) (Jun 6, 2012 in Chinese), Online available at http://www.moh.gov.cn/publicfiles/business/htmlfiles/moh wsbwstjxxzx/s9092/201206/55044.htm (accessed Sep 26, 2012).

3. KPMG, China's $12^{\text {th }}$ Five-Year Plan: Healthcare Sector, KPMG China (May 2011), Online available at http://www.kpmg.com/cn/en/IssuesAndInsights/ArticlesPu blications/Documents/China-12th-Five-Year-PlanHealthcare-201105-3.pdf (accessed Mar 12, 2012).

4. New Zealand Trade \& Enterprise, Expert Guide: Health IT in China, Market Profile (Jul 2012), Online available at http://www.nzte.govt.nz/explore-export-markets/marketresearch-by-industry/Information-and-communicationtechnologies/Documents/North-Asia-Health-IT-in-ChinaJuly-2012.pdf (accessed Sep 2, 2012).

5. G. Teng, M. Li \& V. Li, The Digital Revolution in China, PACS and Networks, $8^{\text {th }}$ Annual MIIT Conference, (Toronto, Canada May 11, 2012), Online available at http://miircam.com/miit2012/2-Li.pdf (accessed Sep 25, 2012). 
6. MOH, Specification for sharing Health Record Documents (2012 in Chinese), Online available at http://www.ahwst.gov.cn:5300/xxgkweb/showGKcontent. aspx?xxnr_id=10290 (accessed Aug 12, 2012).

7. $\mathrm{MOH}$, Specification for sharing Medical Record Documents (2012 in Chinese), Online available at http://www.ahwst.gov.cn:5300/xxgkweb/showGKcontent. aspx?xxnr_id=10291 (accessed Aug 12, 2012).

8. CHIMA, The White Paper on China's Hospital Information Systems (2008), Online available at http://www.chima.org.cn/pe/DataCenter/ShowArticle.asp? ArticleID=612 (accessed Oct 1, 2012).

9. R. Hu, C. Shen \& H. Zou, Health Care System Reform in China: Issues, Challenges and Options (2011), Online available at http://ideas.repec.org/p/cuf/wpaper/517.html (accessed Mar 11, 2013).

10. CSIS, Implementing Health Care Reform Policies in China: Challenges and Opportunities (2011), Online available at

http://csis.org/files/publication/111202_Freeman_Impleme ntingChinaHealthReform_Web.pdf (accessed Mar 11, 2012).

11. W. Huang, Generating Development Strategies of Electronic Health Records in China Based on Stakeholders Analysis (in Chinese), Master Thesis (Research Institute of Medical Informatics, China 2011).

12. B. Naughton, The New Common Economic Program: China's Eleventh Five Year Plan and What It Means, China Leadership Monitor, (16) (2005).

13. Y. Wang, Research on status and development of China's health information standardization (Jun 14, 2012 in Chinese), On-line available at http://md.techex.com/html/2012/article_0414/18664.html (accessed Oct 2, 2012).

14. $\mathrm{MOH}$, Guides for Building Regional Health Information platform for Health Records (2009 in Chinese), Online available at

http://www.chima.org.cn/pe/Article/ShowArticle.asp?Arti cleID=764 (accessed Aug 9, 2012).

15. MOH, Health Record Basic Structure and Data Standards (2009 in Chinese), Online available at http://www.chima.org.cn/pe/Article/ShowArticle.asp?Arti cleID=763 (accessed Aug 9, 2012).

16. MOH, Specification for Preparation of Health Record Basic Dataset (2009 in Chinese), Online available at http://www.chima.org.cn/pe/Article/ShowArticle.asp?Arti cleID=762 (accessed Aug 9, 2012).

17. $\mathrm{MOH}$, Common Data Element Standard for Health Records (2009 in Chinese), Online available at http://www.chima.org.cn/pe/Article/ShowArticle.asp?Arti cleID=761 (accessed Aug 9, 2012).

18. MOH, Basic Dataset Standard for Personal Information (2009 in Chinese), Online available at http://www.chima.org.cn/pe/Article/ShowArticle.asp?Arti cleID=760 (accessed Aug 9, 2012).
19. MOH, Guides for Building Information Platform for Integrated Health Management (2011 in Chinese), Online available at

http://www.moh.gov.cn/publicfiles/business/cmsresources /wsb/cmsrsdocument/doc11824.pdf (accessed Aug 9, 2012).

20. $\mathrm{MOH}$, Technical Solutions for Building Hospital Information Platform Based on Electronic Medical Records (2011 in Chinese), Online available at http://www.moh.gov.cn/publicfiles/business/htmlfiles/moh bgt/s6694/201103/51091.htm (accessed Aug 8, 2012).

21. State Council, 12th Five-Year Plan for Developing Health Services (2012), Online available at http://big5.gov.cn/gate/big5/www.gov.cn/zwgk/201210/19/content_2246908.htm (accessed Mar 11, 2013).

22. Y. Zhang, Status and Tendency of International Health Information Standardisation (Jun 14, 2012 in Chinese), Online available at http://md.techex.com/html/2012/article_0614/18286.html (accessed Oct 2, 2012).

23. Medicare, MediConnect (Aug 24, 2012), Online available at http://www.medicareaustralia.gov.au/provider/patients/me diconnect.jsp (accessed Sep 27, 2012).

24. Department of Health and Aging, HealthConnect Evaluation (2009), Online available at http://www.health.gov.au/internet/main/publishing.nsf/Co ntent/B466CED6B6B1D799CA2577F30017668A/\$File/H ealthConnect.pdf (accessed Sep 27, 2012).

25. NEHTA, Concept of Operations: Relating to the introduction of a Personally Controlled Electronic Health Record System (2011), Online available at http://www.yourhealth.gov.au/internet/yourhealth/publishi ng.nsf/Content/PCEHRS-Introtoc/\$File/Concept\%20of\%20Operations\%20\%20Final.pdf (accessed Sep 26, 2012).

26. J. Zhao, Z. Zhang, H. Guo, Y. Li, W. Xue \& Y. Chen, EHealth in China, Our Practice and Exploration, 31st Annual International Conference of the IEEEE EMBS, (Minneapolis, Minnesota, USA, Sep 2-6, 2009), 4888-93.

27. J. Feng, Y. Song, J. Chen \& W. Zou, Certificateless signature scheme of EMR based DSA, Application Research of Computers, 28(5) (2011) 1910-13.

28. Chinanews.com, Acceleration of China's Health Digitalisation: Over $50 \%$ of Residents have their Electronic Health Records (Feb 27, 2012 in Chinese), Online available at

http://www.chinanews.com/jk/2012/02-27/3701936.shtml (accessed Oct 3, 2012).

29. K. Zita, China Healthcare ICT: Reinventing China's national healthcare system through electronic medical records, telecom networks and advanced IT services, Journal of Emerging Knowledge on Emerging Markets, 1(1) (2009) 47-54. 
30. Zhi Bang Software Technology, IBM Joint Effort for Innovation of Advanced Techniques for Sharing and Analysing Medical Information (2011 in Chinese), Online available at http://www.zbintel.com/wz/52317111.htm (accessed Oct 3, 2012).

31. IBM, IBM - Cloud Medical Solutions (Jul 16, 2012 in Chinese), Online available at

http://www.cloudguide.com.cn/news/show/id/1755.html (accessed Oct 3, 2012).

32. Cisco, Joint Effort by People's Hospital of Peking University and Cisco to Improve Medical Experience by Building Digital Hospitals and Cisco (2012 in Chinese), 12/03/2012, Online available at http://www.cisco.com/web/CN/aboutcisco/news_info/chin a_news/2012/03_12.html (accessed Oct 3, 2012).

33. e800.com.cn, Dell Aids Zhongshan Hospital of Xiaman University in Upgrading Its IT System (Dec 30, 2011 in Chinese), Online available at http://www.e800.com.cn/articles/2011/1230/501128.shtml (accessed Oct 3, 2012).

34. Whatsonxiamen.com, Xiamen Takes the Lead in China in Electronic Health Record System (Aug 25, 2010), Online available at

http://www.whatsonxiamen.com/news14185.html (accessed Sep 25, 2012).

35. E. AbuKhousa, N. Mohamed \& J. Al-Jaroodi, e-Health Cloud: Opportunities and Challenges, Future Internet, 4 (2012) 621-45.

36. NEHTA, E-Health and the Implementation of the PCEHR (2012), Online available at http://www.healthissuescentre.org.au/documents/items/20 12/08/510107-upload-00001.pdf (accessed Sep 29, 2012).

37. WHO, ATLAS: eHealth Country Profiles 2010, (Geneva, Switzerland 2011), Online available at http://www.who.int/goe/publications/ehealth_series_vol1/ en/index.html (accessed Mar 27,2012).

38. P. Shuai \& D. Tang, Electronic health record executive and management (in Chinese), China Science \& Technology Resources Review, 42(5) (2010) 55-60.

39. G. Schneider, Electronic Commerce, $9^{\text {th }}$ edn, Course Technology, Thomson Learning (Boston, MA 2011).

40. Y. Yu, W. Huang, J. Seitz \& N. Wickramasinghe, Evaluation of e-Health in China, $23^{\text {rd }}$ Bled eConference eTrust: Implications for the Individual, Enterprises and Society, (Bled, Slovenia, June 20-23, 2010).

41. Y. Ying, Three Improvement opportunities in China Health IT, New Health Times, (1248) (2009).

42. X. Zhang, International and domestic research on electronic health record, International Journal of Medical Informatics, 34(3) (2012) 236-239.

43. Zhejiang Bureau of Quality and Technical Supervision, Technical Specification of Access Interface for Sharing Health Data (2011 in Chinese), Online available at http://www.zjbts.gov.cn/html/main/bztzggView/241958.ht ml (accessed Aug 8, 2012).
44. C. Herrick, Australians should not opt-in to e-health records (Mar 13, 2012), Online available at http://www.computerworld.com.au/article/418324/australi ans_should_opt-in_e-health_records_auscert/ (accessed Nov 30, 2012).

45. People, MOH: ID Card Number Will Be Personal Health Record ID Number (Sep 15, 2011 in Chinese), Online available at

http://politics.people.com.cn/GB/1027/15669246.html (accessed Mar 13, 2012).

46. X. Lü, An HER-S Architecture and Technologies, Chinese Journal of Biomedicval Engineering, 27(2) (2008) 199205.

47. T. Wu, K. Xu, P. Li, X. Li \& W. Xu, The model of "taking electronic medical records as the core for information construction in hospitals", Chinese Medical Journal, 126(2) (2013) 373-7.

48. S. Liu, B. Zhou, G. Xie, J. Mei, H. Liu, C. Liu, \& L. Qi, Beyond regional health information exchange in China: A practical and industrial-strength approach, Proceedings of the American Medical Informatics Association Symposium, (2011) 824-33.

49. A. Begoyan, An Overview of Interoperability Standards for Electronic Health Records, 10th World Conference On Integrated Design \& Process Technology, (Antalya, Turkey, Jun 3-8, 2007).

50. W. Xu, Z. Guan, G. Cao, H. Zhang, M. Lu,\& T. Li, Analysis and evaluation of the electronic health record standard in China: A comparison with the American national standard ASTM E 1384, International Journal of Medical Informatics, 80 (2011) 555-61.

51. Y. Zhang, Y. Xu, L. Shang \& K. Rao, An investigation into health informatics and related standards in China, International Journal of Medical Informatics, 76 (2007) 614-620.

52. Wikipedia, Health Informatics in China (Sep 14, 2012), Online available at

http://en.wikipedia.org/wiki/Health_informatics_in_China (accessed Sep 25, 2012).

53. Yu, China HIT case study (2006), Online available at http://www.dorenfest.com/doc/chinahitcasestudy.pdf (accessed Feb 7, 2013).

54. H. Guo, T. Dai, H. Hu \& W. Huang, Status, Topics and Tendency of Electronic Health Record Research Bibliometrics Analysis Based on PubMed Database (2010 in Chinese), Online available at http://ziyuan.iiyi.com/source/show/1404176.html (accessed Sep 2, 2012).

55. A. Bahrami, Object Oriented Systems Development, Irwin/McGraw-Hill, (Sydney, Australia 1999).

56. P.S. Wang, Java with Object-Oriented Programming and World Wide Web Applications, Brooks/Cole Publishing Company, (Pacific Grove, CA, USA 1999).

57. K. Li, S. Naganawa, K. Wang, P. Li, K. Kato, X. Li, J. Zhang, \& K. Yamauchi, Study of the Cost-Benefit 
Analysis of Electronic Medical Record Systems in General Hospital in China, J Med Syst, 36 (2012) 3283-91.

58. Gemalto, Electronic healthcare solutions: Putting the patient at the center of modernization (2010), Online available at

http://www.gemalto.com/brochures/download/electronic healthcare.pdf (accessed Feb 6, 2013).

59. C. Xiao \& A. Yu, Medical Smart Card System for Patient Record Management, Science, Technology, and Energy Policy White Paper Competition, Bears Breaking Boundaries (2009), Online available at http://step.berkeley.edu/White_Paper/Xiao_Yu.pdf (accessed Feb 6, 2013).

60. K. McDonald, Use it or lose it - PCEHR for PIP, PULSE+IT (2012), Online available at http://www.pulseitmagazine.com.au/index.php?option=co m_content\&view=article\&id=983:use-it-or-lose-it-pcehrfor-pip\&catid=16:australian-ehealth\&Itemid $=328$ (accessed Sep 25, 2012).

61. World Bank, Fixing the Public Hospital System in China (2010), Online available at http://siteresources.worldbank.org/HEALTHNUTRITION ANDPOPULATION/Resources/2816271285186535266/FixingthePublicHospitalSystem.pdf (accessed Mar 3, 2013).

62. H. Van Vliet, Software Engineering: Principles and Practice, John Wiley \& Sons, Ltd (West Sussex, England, 2008).

63. S. Xu, Advancing Return on Investment Analysis for Electronic Health Record Investment: Impact of Payment Mechanisms and Public Returns, JHIM, 21(4) (2007) 329.

64. World Bank, Toward a Healthy and Harmonious Life in China: Stemming the Rising Tide of Non-Communicable Diseases (2011), Online available at http://www.worldbank.org/en/news/feature/2011/07/26/to ward-health-harmonious-life-china-stemming-rising-tideof-non-communicable-diseases (accessed Feb 6, 2013).

65. IBM, Healthcare 2015: Win-win or lose-lose? (2006), Online available at http://www935.ibm.com/services/us/gbs/bus/html/healtcare-2015win-win.html (accessed Feb 6, 2013).

66. C.M. Showell, Citizens, patients and policy: a challenge for Australia's national electronic health record, Health Information Management Journal, 40(2) (2011) 29-43.

67. J. Church, D. Saunders, M. Wanke, R. Pong, C. Spooner \& M. Dorgan, Citizen participation in health decisionmaking: past experience and future prospects, Journal of Public Health Policy. 23(1) (2002) 12-32.

68. C. Tuohy \& R. Evans, Pushing on a string: the decentralization of health planning in Ontario. In R. Gotembiewski \& A. Wildavsky eds. The Costs of Federalism, Transaction Books (New Brunswick NJ 1986).
69. B. Packham, Tony Abbott says Labor may seek new Queensland flood levy, The Australian (2013), 28/01/2013, Online available at

http://www.theaustralian.com.au/national-affairs/politicsnews/tony-abbott-says-labor-may-seek-new-queenslandflood-levy/story-fn59nqld-1226563573428 (accessed Mar 15, 2013).

70. G. Ng, Private hospitals eye China market as middle class seeks quality care, The China Post (Jul 17, 2012), Online available at http://www.chinapost.com.tw/china/localnews/beijing/2012/07/17/347892/Private-hospitals.htm (accessed Mar 15, 2013).

71. IMAPAC, Private Hospital World China (2013), Online available at

http://www.imapac.com/index.php?page=PrivateHospital WorldChina2013 (accessed Mar 15, 2013).

72. European Communities, Accelerating the Development of the eHealth Market in Europe (2007), Online available at http://www.ehealthnews.eu/images/stories/pdf/lmi-reportfinal-2007dec.pdf (accessed Feb 6, 2013).

73. World Bank, China 2030: Building a Modern, Harmonious, and Creative Society (2013), Online available at

http://www.worldbank.org/content/dam/Worldbank/docu ment/China-2030-complete.pdf (accessed Apr 22, 2013).

74. National Bureau of Statistics of China, Preliminary Accounting Results of GDP in 2012 (Jan 22, 2013), Online available at http://www.stats.gov.cn/english/pressrelease/t20130122_4 02868023.htm (accessed Apr 22, 2013).

75. M. Li \& L. Yin, A Study on Issues and Strategies Concerning the IT-based Security System for Whole People Health, CHINA SCIENCE \& TECHNOLOGY RESOURCES REVIEW, 42(4) (2010) 37-42.

76. C. Wang, W. Yang \& S. Ju, Research and Implementation of Electronic Health Record Signature System Based on CES, Computer Engineering, 36(16) (2010) 283-5.

77. B.S. Alhaqbani, Privacy and Trust Management for Electronic Health Records, Thesis, Queensland University of Technology (2010).

78. X. Mao \& Y. Xiang, 'Philosophical thoughts on privacy protection in ehealth age', Journal of Wuhan Uni. of Sci. \& Tech. (Social Science Edition), 10(1) (2008) 32.

79. WHO, Legal frameworks for eHealth (2012), Online available at http://whqlibdoc.who.int/publications/2012/978924150314 3_eng.pdf (accessed Feb 7, 2013).

80. P.C. Tang, J.S. Ash, D.W. Bates, J.M., Overhage \& D.Z. Sands, Personal Health Records: Definitions, Benefits, and Strategies for Overcoming Barriers to Adoption, J Am Med Inform Assoc, 13(2) (2006) 121-126.

81. MobiThinking, China passes 1 billion mobile subscribers, passes 400 million mobile Web users and overtakes US as world's top smartphone market (2012), Online available at 
http://mobithinking.com/blog/china-top-mobile-market (accessed Oct 4, 2012).

82. X. Zhang, B. Li, Z. Yao, L. Liu \& H. Chen, Chronic Disease Management System Based on eHealth Concept in China, The First International Conference on Global Health Challenges, (2012) 55-9.

83. J. Puentes, J. Montagner, L. Lecornu \& J. Lähteenmäki, Quality Analysis of Sensors Data for Personal Health Records on Mobile Devices in Pervasive Health Knowledge Management (editor: R. Bali, I. Troshani, S. Goldberg \& N. Wickramasinghe), Springer (2013) 103-33.

84. Xinhua, Number of International Visitors Entering China Increases by 10\% Annually in the Century (Apr 25, 2012 in Chinese), Online available at http://news.xinhuanet.com/politics/201204/25/c_111842921.htm (accessed Mar 10, 2013).

85. People, Chinese tourists promote tourism growth in Southeast Asia (Jan 23, 2013 in Chinese), Online available at http://world.people.com.cn/n/2013/0123/c5750720295553.html (accessed Mar 10, 2013). 